\title{
Address of Pope John Paul II to the Participants in the International Congress on "Life-Sustaining Treatments and Vegetative State: Scientific Advances and Ethical Dilemmas", Saturday, 20 March 2004
}

Distinguished Ladies and Gentlemen,

1. I cordially greet all of you who took part in the International Congress: "Life-Sustaining Treatments and Vegetative State: Scientific Advances and Ethical Dilemmas". I wish to extend a special greeting to Bishop Elio Sgreccia, Vice-President of the Pontifical Academy for Life, and to Prof. Gian Luigi Gigli, President of the International Federation of Catholic Medical Associations and selfless champion of the fundamental value of life, who has kindly expressed your shared feelings.

This important Congress, organized jointly by the Pontifical Academy for Life and the International Federation of Catholic Medical Associations, is dealing with a very significant issue: the clinical condition called the "vegetative state". The complex scientific, ethical, social and pastoral implications of such a condition require in-depth reflections and a fruitful interdisciplinary dialogue, as evidenced by the intense and carefully structured programme of your work sessions.

2. With deep esteem and sincere hope, the Church encourages the efforts of men and women of science who, sometimes at great sacrifice, daily dedicate their task of study and research to the improvement of the diagnostic, therapeutic, prognostic and rehabilitative possibilities confronting those patients who rely completely on those who care for and assist them. The person in a vegetative state, in fact, shows no evident sign of self-awareness or of awareness of the environment, and seems unable to interact with others or to react to specific stimuli.

Scientists and researchers realize that one must, first of all, arrive at a correct diagnosis, which usually requires prolonged and careful observation in specialized centres, given also the high number of diagnostic errors reported in the literature. Moreover, not a few of these persons, with appropriate treatment and with specific rehabilitation programmes, have been able to emerge from a vegetative state. On the contrary, many others unfortunately remain prisoners of their condition even for long stretches of time and without needing technological support.

In particular, the term permanent vegetative state has been coined to indicate the condition of those patients whose "vegetative state" continues for over a year. Actually, there is no different diagnosis that corresponds to such a definition, but only a conventional prognostic judgment, relative to the fact that the recovery of patients, statistically speaking, is ever more difficult as the condition of vegetative state is prolonged in time.

However, we must neither forget nor underestimate that there are well-documented cases of at least partial recovery even after many years; we can thus state that medical science, up until now, is still unable to predict 
with certainty who among patients in this condition will recover and who will not.

3. Faced with patients in similar clinical conditions, there are some who cast doubt on the persistence of the "human quality" itself, almost as if the adjective "vegetative" (whose use is now solidly established), which symbolically describes a clinical state, could or should be instead applied to the sick as such, actually demeaning their value and personal dignity. In this sense, it must be noted that this term, even when confined to the clinical context, is certainly not the most felicitous when applied to human beings.

In opposition to such trends of thought, I feel the duty to reaffirm strongly that the intrinsic value and personal dignity of every human being do not change, no matter what the concrete circumstances of his or her life. A man, even if seriously ill or disabled in the exercise of his highest functions, is and always will be a man, and he will never become a "vegetable" or an "animal".

Even our brothers and sisters who find themselves in the clinical condition of a "vegetative state" retain their human dignity in all its fullness. The loving gaze of God the Father continues to fall upon them, acknowledging them as his sons and daughters, especially in need of help.

4. Medical doctors and health-care personnel, society and the Church have moral duties toward these persons from which they cannot exempt themselves without lessening the demands both of professional ethics and human and Christian solidarity.

The sick person in a vegetative state, awaiting recovery or a natural end, still has the right to basic health care (nutrition, hydration, cleanliness, warmth, etc.), and to the prevention of complications related to his confinement to bed. He also has the right to appropriate rehabilitative care and to be monitored for clinical signs of eventual recovery.

I should like particularly to underline how the administration of water and food, even when provided by artificial means, always represents a natural means of preserving life, not a medical act. Its use, furthermore, should be considered, in principle, ordinary and proportionate, and as such morally obligatory, insofar as and until it is seen to have attained its proper finality, which in the present case consists in providing nourishment to the patient and alleviation of his suffering.

The obligation to provide the "normal care due to the sick in such cases" (Congregation for the Doctrine of the Faith, Iura et Bona, p. IV) includes, in fact, the use of nutrition and hydration (cf. Pontifical Council "Cor Unum", Dans le Cadre, 2, 4, 4; Pontifical Council for Pastoral Assistance to Health Care Workers, Charter of Health Care Workers, n. 120). The evaluation of probabilities, founded on waning hopes for recovery when the vegetative state is prolonged beyond a year, cannot ethically justify the cessation or interruption of minimal care for the patient, including nutrition and hydration. Death by starvation or dehydration is, in fact, the only possible outcome as a result of their withdrawal. In this sense it ends up becoming, if done knowingly and willingly, true and proper euthanasia by omission.

In this regard, I recall what I wrote in the Encyclical Evangelium Vitae, making it clear that "by euthanasia in the true and proper sense must be understood an action or omission which by its very nature and intention brings about death, with the purpose of eliminating all pain"; such an act is always "a serious violation of the law of God, since it is the deliberate and morally unacceptable killing of a human person" (n. 65).

Besides, the moral principle is well known, according to which even the simple doubt of being in the presence of a living person already imposes the obligation of full respect and of abstaining from any act that aims at anticipating the person's death.

5. Considerations about the "quality of life", often actually dictated by psychological, social and economic pressures, cannot take precedence over general principles.

First of all, no evaluation of costs can outweigh the value of the fundamental good which we are trying to protect, that of human life. Moreover, to admit that decisions regarding man's life can be based on the external acknowledgment of its quality, is the same as acknowledging that increasing and decreasing levels of quality of life, and therefore of human dignity, can be attributed from an external perspective to any subject, thus introducing into social relations a discriminatory and eugenic principle.

Moreover, it is not possible to rule out a priori that the withdrawal of nutrition and hydration, as reported by authoritative studies, is the source of considerable suffering for the sick person, even if we can see only the reactions at the level of the autonomic nervous system or of gestures. Modern clinical neurophysiology and neuro-imaging techniques, in fact, seem to point to the lasting quality in these patients of elementary forms of communication and analysis of stimuli.

6. However, it is not enough to reaffirm the general principle according to which the value of a man's life 
cannot be made subordinate to any judgment of its quality expressed by other men; it is necessary to promote the taking of positive actions as a stand against pressures to withdraw hydration and nutrition as a way to put an end to the lives of these patients.

It is necessary, above all, to support those families who have had one of their loved ones struck down by this terrible clinical condition. They cannot be left alone with their heavy human, psychological and financial burden. Although the care for these patients is not, in general, particularly costly, society must allot sufficient resources for the care of this sort of frailty, by way of bringing about appropriate, concrete initiatives such as, for example, the creation of a network of awakening centres with specialized treatment and rehabilitation programmes; financial support and home assistance for families when patients are moved back home at the end of intensive rehabilitation programmes; the establishment of facilities which can accommodate those cases in which there is no family able to deal with the problem or to provide "breaks" for those families who are at risk of psychological and moral burn-out.

Proper care for these patients and their families should, moreover, include the presence and the witness of a medical doctor and an entire team, who are asked to help the family understand that they are there as allies who are in this struggle with them. The participation of volunteers represents a basic support to enable the family to break out of its isolation and to help it to realize that it is a precious and not a forsaken part of the social fabric.

In these situations, then, spiritual counselling and pastoral aid are particularly important as help for recovering the deepest meaning of an apparently desperate condition.

7. Distinguished Ladies and Gentlemen, in conclusion I exhort you, as men and women of science responsible for the dignity of the medical profession, to guard jealously the principle according to which the true task of medicine is "to cure if possible, always to care".

As a pledge and support of this, your authentic humanitarian mission to give comfort and support to your suffering brothers and sisters, I remind you of the words of Jesus:? "Amen, I say to you, whatever you did for one of these least brothers of mine, you did for me" (Mt 25: 40).

In this light, I invoke upon you the assistance of him, whom a meaningful saying of the Church Fathers describes as Christus medicus, and in entrusting your work to the protection of Mary, Consoler of the sick and Comforter of the dying, I lovingly bestow on all of you a special Apostolic Blessing.

Pope John Paul II 